\title{
Oscilloscope Device
}

National Cancer Institute

\section{Source}

National Cancer Institute. Oscilloscope Device. NCI Thesaurus. Code C50089.

An electronic device designed to display electrical measurements, typically as a waveform on a cathode ray tube. 